\title{
Advertisements as Authentic Materials in Business English Class
}

\author{
Vesna Lazović"
}

\begin{abstract}
Authentic materials frequently complement coursebooks since they increase learner motivation and provide a realistic context for tasks relating to learners' needs. However, using language from natural texts instead of ready-made examples can be counterproductive if not appropriately adapted. For that reason, the ESP teacher must consider the learner's knowledge of language when preparing tasks, as authentic materials often contain difficult language, unnecessary vocabulary items, and complex language structures. This paper, first, summarizes the main advantages of using such materials in teaching and then focuses on the use of bank advertisements in Business English classes. In order to be properly implemented, these advertisements need to be analyzed in terms of their most frequent features at different linguistic levels. This analysis can help both ESP teachers to relate language instruction to particular universal characteristics of the register and ESP students to acquire language more naturally. Finally, the paper includes several ideas for exercises focusing on different language skills aimed at intermediate and upper-intermediate students.
\end{abstract}

Key words: authentic materials, advertisements, bank advertising, Business English class

\footnotetext{
* Faculty of Philosophy, University of Novi Sad; lazovicvesna@ff.uns.ac.rs
} 


\section{Introduction}

The teaching and learning situation has changed dramatically after communicative language teaching came into existence in the late 1970s and the need for authenticity reappeared. The concept of actual language use in language teaching was then introduced and the language classroom was linked to the reality of the outside world.

Although the issue of authenticity has been discussed and debated extensively in the field of linguistics, materials development and pedagogy for at least four decades, a consensus has not been reached on a precise definition (Lee 1995). Some of the authors tried to simplify the matter by underlining that the term authentic is "reserved for textual material prepared for the consumption of native speakers, without any type of adaptation or abbreviation for the benefit of the foreign language student" (Carney and Franciulli 1992, 3). However, defining authenticity and implementing it, especially in education, has become a very complex process. Gilmore $(2008,68)$ emphasizes this complexity by highlighting a variety of research fields in which authenticity has been explored, including discourse and conversational analysis, pragmatics, cross-cultural studies, sociolinguistics, ethnology, second language acquisition, and motivation research, among others.

This paper, first, tries to summarize the common definitions of authenticity together with the main advantages of using such materials in teaching. Furthermore, it discusses the necessity of a thorough pre-analysis of materials before they are brought to class. Finally, it concludes with several ideas for exercises focusing on different language skills aimed at intermediate and upper-intermediate students.

\section{Definitions of authenticity}

The notion of authenticity was originally introduced to distinguish between artificially simplified texts and unmodified real texts (Thornbury 2006). Nonetheless, the problem of defining authenticity has become very complex over the years primarily because researchers mainly investigated the concept within their fields of specialization. Gilmore (2008) warns about the different readings and definitions which can further lead to terminological confusions.

One of the first widely accepted definitions was the one proposed by Morrow (1977, 13) who suggests that an authentic text is "a stretch of real language, produced by a real speaker or writer for a real audience and designed to convey a real message of some sort." Similarly, Widdowson $(1983,30)$ attributes authenticity to texts produced by native speakers which inevitably have a normal communicative purpose. These two early definitions center around text authenticity by emphasizing a real sender and a real receiver of the message. 
Referring to authenticity in the language classroom, McDonough and Shaw (1993, 43) point out that authenticity implies a close approximation of the world outside the classroom in terms of both the selection of language material and the activities used for practising. In other words, authenticity is the result of acts of authentication, by students and their teacher, of the learning process and the language used in it (van Lier 1996, 128).

For the purpose of this paper dealing with authenticity in foreign language education, the most appropriate definition of authenticity would be Mishan's layered description $(2005,18)$, where authenticity is seen as a set of the following five criteria: (1) provenance and authorship of the text; (2) original communicative and socio-cultural purpose of the text; (3) original context of the text; (4) learning activity engendered by the text; and (5) learners' attitudes to the text and the activity pertaining to it.

\section{Authenticity in language education}

Following Mishan's thorough discussion and investigation into authenticity in language education (2005), it can be concluded that authenticity is a complex process with the key components being manifested in three domains, namely, authenticity of texts, authenticity of tasks, and learner authenticity.

\subsection{Authenticity of texts}

Authentic texts are textual materials aimed at native speakers which can be used as classroom materials with or without adaptation and/or simplification for the foreign language student. However, the two most common concerns regarding the use of such texts are text difficulty and the loss of authenticity. Most commonly, texts for native speakers abound in difficult language, unnecessary vocabulary items, and complex language structures. Therefore, the question remains whether a text loses its authenticity if it is adapted and used for pedagogical purposes. Generally speaking, absolute authenticity is impossible in classroom settings, because it is destroyed whenever a text is used for teaching purposes, i.e. whenever a text contains traces of language teaching intervention (Morrow 1977; Chavez 1998; Joy 2011).

Furthermore, there are two opposing standpoints in the literature regarding the modification of texts. On the one hand, some authors highlight the complexity of such texts, which are very often too difficult to be comprehended by language learners (e.g. Widdowson 2003; Mishan 2005; Khaniya 2006). For that reason, texts should be simplified and adapted to the learner's knowledge of the respective language. This is especially important at lower levels, as learners may not be able to respond to a text appropriately, which can further cause frustration, confusion, and demotivation (Guariento and 


\begin{tabular}{ll}
\hline & Important Factors in Choosing Authentic Reading Material \\
\hline Suitability of Content & Does the text interest the student? \\
& Is it relevant to the student's needs? \\
& Does it represent the type of material that the student will use outside of the classroom? \\
Exploitability & Can the text be exploited for teaching purposes? \\
& For what purpose should the text be exploited? \\
& What skills/strategies can be developed by exploiting the text? \\
Readability & Is the text too easy/difficult for the student? \\
& Is it structurally too demanding/complex? \\
Presentation & How much new vocabulary does it contain? Is it relevant? \\
& Does it "look" authentic? \\
& Is it "attractive"? \\
& Does it grab the student's attention? \\
& Does it make him want to read more?
\end{tabular}

Table 1: Checklist for selecting authentic materials, Berardo $(2006,63)$.

Morley 2001, 348; Gilmore 2007, 109). This approach is a so-called loose approach to authentic texts, since text alterations are justified by pedagogical reasoning. On the other hand, there is a stricter approach to authenticity. Adams (1995) states that materials are authentic if the language data are unaltered and produced originally for non-teaching purposes conveying a real message. Proponents of this view are generally against any text simplifications and suggest task simplification instead (e.g. Morrow 1977; Bacon and Finnemann 1990; Berardo 2006).

Whatever the standpoint, with SLA research becoming increasingly pedagogically focused, Mishan $(2005,21)$ argues that authentic texts in language learning should be used since they enhance language acquisition. She also (ibid, 37) adds that their use demands greater personal investment on the part of the learner, which is how the vital connection is made between the classroom and the real world.

Anyhow, whenever a text is to be selected, a teacher always has to consider a number of important factors, such as curricular goals, the students' age, their level of language proficiency, and their interests and needs (Khaniya 2006, 21). Berardo $(2006,63)$ suggests a check-list for teachers for selecting authentic materials, particularly for choosing authentic reading material, presented in Table 1.

Unlike pedagogical texts in course books, authentic materials do not highlight particular linguistic or grammatical features but rather fulfil a particular purpose, for example, convey information, instruct, or persuade. For that reason, a proper selection and adaptation of authentic texts are required. Only then can teachers focus on designing tasks which suit the learners' needs. 


\subsection{Authenticity of tasks}

Many researchers suggest that with a task-based language learning approach, authentic materials can be used even with beginners, since the level of difficulty is modified by adapting the task and not the text itself (Nunan 1989; Mishan 2005). In such a way, task design can solve the problem of text difficulty.

When incorporating authentic texts in foreign language classes, crucial questions should be: (a) what is to be achieved with classroom materials? and, consequently, (b) what kind of tasks ought to be designed around these materials? According to Mishan (2005) and Gilmore (2008), the teacher's goal is to help learners become communicatively competent, i.e. to communicate effectively in the target language. This is possible only if classroom activities acknowledge the communicative purpose of an authentic text. Teachers can use any materials, as long as they serve that purpose.

In order to design authentic tasks, it is vital to consider the six guidelines proposed by Mishan $(2005,75)$ with regard to task authenticity:

1. reflect the original communicative purpose of the text on which they are based

2. be appropriate to the text on which they are based

3. elicit response to/engagement with the text on which they are based

4. approximate real-life tasks

5. activate learners' existing knowledge of the target language and culture

6. involve purposeful communication between learners.

Mishan's (2005) approach to designing authentic tasks around authentic materials always begins with the identification of the communicative purpose of a text. Thereafter, the teacher can select between the different task types. To illustrate, advertisements have a persuasive communicative purpose, hence, the teacher can design different tasks where learners analyse how the communicative purpose of the advertisement is achieved. In Table 2, several examples of authentic tasks are presented, which belong to three different task types, as described by Mishan (2005, 90).

\begin{tabular}{|c|c|c|}
\hline Task Type & Description & Examples \\
\hline Inferencing & $\begin{array}{l}\text { Inferring/interpreting information/concepts (in- } \\
\text { cluding cultural) from audio, written, visual or } \\
\text { audio-visual input. }\end{array}$ & $\begin{array}{l}\text { Find several advertisements and infer the target } \\
\text { audience. } \\
\text { Identify the cultural concepts in advertisements. }\end{array}$ \\
\hline Extraction & $\begin{array}{l}\text { Extracting factual information from audio, writ- } \\
\text { ten, visual or audio-visual input. }\end{array}$ & Extract factual information from advertisements. \\
\hline Analysis & $\begin{array}{l}\text { Raising awareness of linguistic forms and func- } \\
\text { tions and of figurative use of language. }\end{array}$ & $\begin{array}{l}\text { Analyse how advertisements achieve impact. } \\
\text { Analyse conversational strategies. }\end{array}$ \\
\hline
\end{tabular}

Table 2: Advertisements as examples within three different task types (Mishan 2005, 90). 


\subsection{Learner authenticity}

Together with the appropriate choice of authentic texts and the design of authentic tasks, authenticity in language learning depends on the learner who is an active subject in the learning process. The learner is the one who experiences and evaluates the authenticity of texts and the tasks designed around them (Mishan 2005, 18). The authenticity-centred approach concentrates on learners and their experiences, attitudes, needs, and emotions. Authentic materials can be selected to meet the needs and interests of specific learners, which textbooks targeted at an international audience sometimes fail to address (Morrison 1989; McGarry 1995; Mishan 2005).

Unless the teacher prepares authentic texts and tasks to tailor learners' needs, learners will not be able to understand the purpose of these real-life materials used in a classroom setting. Authenticity in language learning depends on the learner's perception of what is authentic, that is, the learner's response (Arnold 1991, 239-240; Mishan 2005, 18). More precisely, authenticity ought to be reflected in tasks which relate to the learning experience.

Lee (1995) also claims that authentic materials must be learner-authentic. In other words, they need to be motivating, interesting, and useful. Moreover, Joy (2011) argues that authenticity is a process of personal engagement, in which learners must be genuinely interested. Teachers should construct relevant classroom contexts in order to make the learning process real for learners (Nation 2009) and implement materials and design tasks which will enable learners to meaningfully and purposefully use the language (Castillo Losada et al. 2017).

\section{Advertisements as authentic materials}

The authenticity of the language can help language learners develop their communicative competence (Tomlinson 1998). The significance of authenticity has been emphasized by various authors as a relevant feature in ESP methodology (Breen, 1985; Rogers and Medley 1988; Guariento and Morley 2001; Gilmore 2004, 2007; Berardo 2006).

According to Shrum and Glisan (2000,133), authentic materials "provide an effective means for presenting real language, integrating culture, and heightening comprehension." Beresova (2015) claims that authentic materials can be more appropriate for advanced L2 readers than pedagogically modified texts in raising cultural awareness. They can be used to pre-teach cultural traits, increase learners' knowledge about the culture (e.g. holidays, history, tradition). Such materials are often thought to contain more realistic and natural examples of language use than the ones found in course books and 
other teaching materials (Richards and Schmidt 2002, 42). The main advantages of using such materials could be summarized as follows (Richards, 2001):

- they expose learners to real language;

- they have a positive effect on learner motivation;

- they improve their language production;

- they increase their confidence;

- they raise their awareness of natural speech;

- they provide authentic cultural information about the target culture;

- they relate more closely to learners' needs;

- they support a more creative approach to teaching;

- they develop their interest in the real use of the target language.

This paper will illustrate the use of advertisements as authentic materials in Business English classes. Advertisements in the media are a rich source for educational use, since they are abundant in a wide variety of psychological, emotional, and cultural messages. They are also a valuable source of habits, customs, and social behaviour (McCarthy and Carter 1994, 150). They can be used as learning tools for teaching vocabulary, grammar, and writing concepts. For example, Brickman (1992) uses them to exemplify writing models presented in class. He argues that advertisements can be effective, when carefully chosen, even in the basic skills classroom, since they can help students sharpen their critical thinking skills. Furthermore, learners can collect those advertisements which contain examples of vocabulary taught in class, such as wordplays, idioms, and metaphors. Picken's article (2000) reviews work in the areas of language awareness, language play, and culture in relation to the use of advertisements in foreign language teaching. Stamatelou (2015) underlines the contribution of written advertisements to language learning, paying special attention to how macro-level and micro-level discourse features of advertising can be taught. She further points out that teaching discourse in EFL classrooms using whole written advertisement texts contributes to raising learners' language awareness and to developing their language learning, because it involves the highlighting of linguistic, cultural, and socio-cultural domains (32).

Interestingly enough, although there is a vast amount of authentic materials available as teaching resources, including advertisements, there are very few guidelines for teachers on how to incorporate them successfully into the language classroom. Kramsch (1993) gives detailed suggestions on how advertisements and other authentic materials can be used but does not elaborate how to select them or for what to use them. Jacobson et al. (2003) provide useful ideas on how to use different authentic materials and demonstrate the wide variety of literacy activities that can be used when exploring a single theme but do not mention advertisements in particular. Autio $(2012,6)$ emphasizes that there actually is no handbook on the implementation of authentic texts or the design of authentic tasks for cultural education and includes a material package with practical guidelines for the application of authentic materials as cultural mirrors. 
Here, the following steps are suggested for approaching authentic materials:

1. selecting materials and identifying the goals of teaching.

Teachers should decide which authentic materials they want to use and for what reasons.

2. pre-examining features of a text.

Teachers need to pre-examine features of a text and specific register in advance (linguistic and/or non-linguistic features) focusing on the targeted aspects to be learnt, including both the content and the form;

3. adapting the text and designing the tasks.

Teachers should adapt the text to the students' level of language knowledge before using it in class.

Since the preparation of authentic materials can be very time-consuming, the first step is the most essential because without a clear purpose in mind, all the hard work can be in vain. Osborne $(2005,74)$ suggests that the ESP instructor must always incorporate authentic texts that are meaningful to students. The fact that a text is authentic does not automatically mean that it is relevant, which can lead to situations where learners report authentic materials to be significantly less interesting than artificial materials (Peacock 1997). Liu (2016) also advises language teachers to make use of graded tasks to guide the students through its difficulties from simple to more complicated ones. Finally, Gilmore (2008: 97) warns that teachers should not overload the learners' language capacity by asking them to analyse input for meaning and form simultaneously. Rather, they should focus on meaning first before shifting attention to language forms (Willis 1996).

\subsection{Main features of advertisements}

In order to use advertisements, the teacher needs to get acquainted with the previous analyses and pre-examine features to be used in class. Only with the thorough insight into different aspects of advertisements can they further be implemented in ESP teaching.

To start with, many linguists have dealt with the analysis of advertising language from the linguistic point of view and specified devices used in advertising texts. For instance, Leech's (1966) work on English-language advertising in 1960s Britain highlights the extensive repertoire of linguistic choices available to copywriters when creating advertising material; Rees (1982) shows how slogans have been used; Cook (1992) focuses on parallelism, metaphor, metonymy, homophones, puns, parody, and rhyme; Myers (1994) includes alliteration, assonance, rhyme, homophones, question forms, ellipsis, parallelism, and puns. In a general survey, Brierley (2002) lists language games, repetition, similes, parallelism, paradox, omission, and ambiguity, while Tanaka (1994) concentrates on the use of puns and metaphors, etc. Vestergaard and Schroder (1985) illustrate 
the range of techniques advertisers use to achieve emphasis and special effects. All of these studies reveal some universal language features of advertisements across languages:

1. at the phonological level: alliteration, rhythm and rhyme, repetition, sound symbolism;

2. at the orthographic level: deviations in spelling, capitalization;

3. at the lexical level: trigger words, brand names, slogans, catch phrases;

4. at the grammatical level: structural simplicity, ellipsis, imperatives, superlatives;

5. at the semantic level: metaphors, metonymy, word plays, ambiguity;

6. at the pragmatic level: direct appeal to the recipients, speech acts of persuasion.

This list does not attempt to be exhaustive but only emphasizes the fact that some uniform features appear in advertisements regardless of language or culture. A discoursebased view of advertising language confirms that all of these characteristics have the same functions - catching our attention and appealing to our imagination; increasing recognition and enhancing the memorizing effect; making the advertisement easy to repeat and remember (Leech 1966, 29; Dyer 1982, 140).

\subsection{Examples of authentic tasks for classroom use}

Picken $(2000,341)$ notices that advertisements still seem to be rarely used in mainstream EFL texts, most commonly in activities related to job advertisements. Stamatelou (2015, 27) further investigates the use of advertisements in EFL course books and concludes that advertising texts are under-exploited, both qualitatively and quantitatively. The micro-level and macro-level discourse features reflecting the functions of advertising texts are neither highlighted nor interrelated.

This can be confirmed if any typical Business English course book (B1 level CEFR) is taken into consideration. For example, in Allison and Emmerson $(2013,55)$ there is only one instance of job advertisements in relation to a role-play where students revise the most common questions and answers at a job interview. Moreover, in Cotton, Falvey, and Kent $(2011,44-51)$ a whole unit is dedicated to the concept of advertising. However, the exercises mainly serve as a trigger for speaking practice and introduce vocabulary which is broadly connected to advertising (e.g. words for different methods of advertising or verbs to do with advertising). They neither refer to the register of advertising nor do they indicate any of the lexico-grammatical features. As was mentioned above, advertisements provide an excellent source of varied and comprehensible input for language learners and should be used in language learning settings. As such, they can complement materials in the compulsory Business English course book in order to encourage learners to further explore language use on their own. They are likely to increase learner motivation while providing a realistic context for tasks relating to learners' needs. The sample tasks presented here are all based on the discussion and findings in Lazović (2014a, 2014b, 2015) and are primarily designed for Business English classes. Since all of the examples are taken from the collected corpus of online 
bank advertisements in the UK, they are suitable for students of economics, marketing, business, banking, management, etc. In situations where learners need specialised language for professional development, authentic texts might be more motivating because learners recognise them as useful for their future career (Mishan 2005, 27). Following the same pattern, other advertisements can, of course, also be used, depending on the learner's interests and needs.

In the following section, several ideas for exercises are presented, focusing on different language skills aimed at intermediate and upper-intermediate students (B1-B2 level CEFR). In the vocabulary exercise, for example, frequent words and their collocational patterns are practised; while in the grammar exercise, the use of imperatives is reinforced. Regarding productive language skills, students can improve their speaking by discussing the strategies banks use online and by elaborating on the reasons of their effectiveness; alternatively, they can be asked to change the genre from descriptive texts to that of advertising texts.

\subsubsection{Vocabulary exercises}

The following examples can help students learn and revise frequent words and expressions in advertisements.

Example 1 - Fill in the missing words in these sentences

1 When you borrow money from banks, pay attention to the i....... r....... they charge.

2 Which kind of s........ a........ suits you best?

3 Have you checked if you are p........ the right amount of t........?

4 Recipient banks abroad may c........ a f........ for receiving payments.

Example 2 - Suggest at least three words that could collocate with each of the nouns below

account

[DEPOSIT, INVESTMENT, SAVINGS] card

[CREDIT, DEBIT, PREPAID]

Example 3 - The following captions from bank advertisements all include instances of figurative language. Name the figures of speech used in each example and discuss their impact on the target audience.

1 Wherever you go, your bank travels with you

[METAPHOR]

2 A range of low rate, low deposit mortgages

[PARALLELISM]

3 Turn your small change into something big

[ANTITHESIS]

4 A successful career you can bank upon

[WORDPLAY] 


\subsubsection{Grammar exercises}

Grammatical exercises can encourage students to understand the typical grammatical patterns used in advertisements.

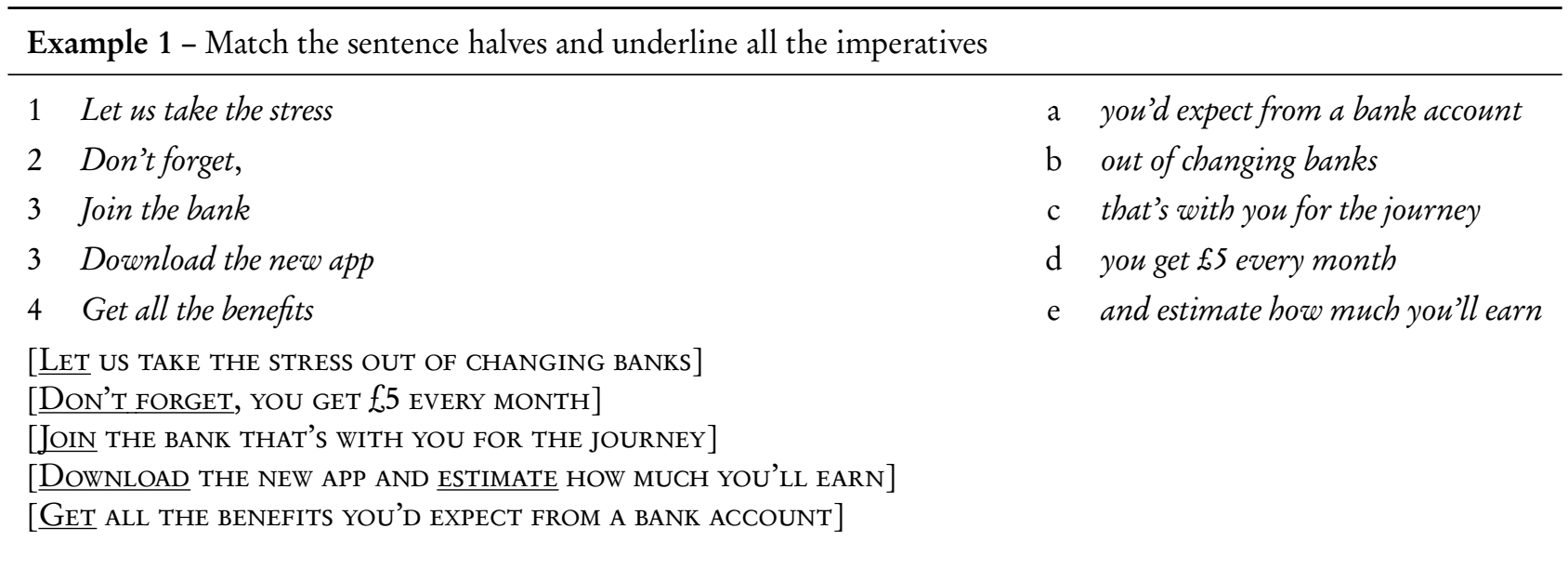

Example 2 - Recover the missing elements in the following bank advertisements and discuss the main function of ellipsis in advertising

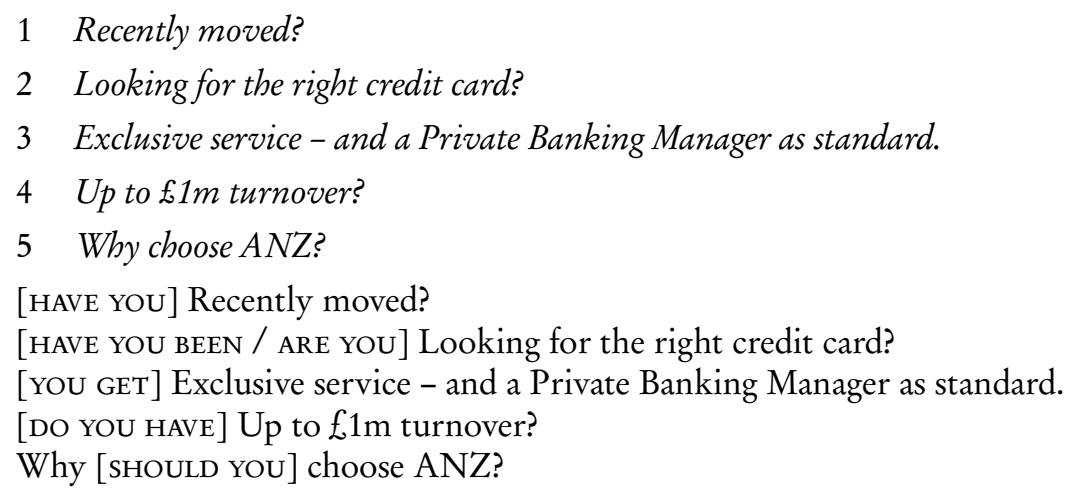

Example 3 - Find the advertisements with the intentional grammatical errors (e.g., 'kidz accounts' or the famous McDonald's slogan 'I'm lovin' $\left.i t^{\prime}\right)$. Explain the implications. 


\title{
4.2.3 Speaking exercises
}

As a supplement to the course books, authentic advertisements may provide learners with the various genuine visual and verbal elements which can help them improve their oral skills.

Example 1 - Find several online bank advertisements. Discuss the strategies they use for attracting attention. Do they appeal to you? Justify.

Example 2 - Describe the advertisements and compare advertising approaches that banks take to attract various groups of consumers (e.g. a busy mother packing groceries into a van together with her children; a happy couple drinking wine in a restaurant; a retired man distrustfully looking at his laptop, etc.)

Example 3 - Discuss the interrelation between a visual and verbal component in the advertisements (e.g. a picture of a moped together with a caption 'Looking for a loan?' or an advertisement featuring a young girl going downstairs with her dog reading ' $1 \%$ off loans for our loyal customers').

\subsubsection{Writing exercises}

Learners could be instructed to consider typical features when writing advertisements or change the genre of descriptive texts to that of advertising texts.

Example 1 - Read the passage about the bank service. Think of the ways to present the information in the form of an advertisement. Write two possible versions.

\begin{abstract}
The Credit Card for Purchases
When you start using your new Card for purchases you'll pay $0 \%$ for 18 months from the date of your account opening. If you bave any major purchases planned, your Card may belp to ease the cost. In addition, you pay $0 \%$ interest on balance transfers from other credit and store cards - for a full 9 months from the date you open your account (3\% balance transfer fee applies, minimum £5).The smallest amount you can transfer is $£ 100$. The total amount of balances you can transfer cannot be more than $95 \%$ of your credit limit. If the total transfer you want to make is above your available credit limit, we may allow you to transfer part of this amount. You cannot transfer balances from other Group accounts. At the end of the $0 \%$ period, if you baven't paid off the amount of the balance transfer and/or the purchases in full, interest will become payable on the remaining amount at your standard balance transfer or purchase rate.
\end{abstract}

(taken from www.santander.co.uk)

Example 2 - Below is an imaginary example of a bank advertisement. Identify the problems and write an improved version.

\section{Personal loans between $£ 7,000$ and $£ 15,000$}

Unless you open a bank account at Crissfold bank, you'll not be able to get a loan.

If you don't apply online, you'll wait approximately seven days for a transfer of funds.

If you don't own our special bankcard, additional fees apply.

You have to have the minimum of $£ 1000$ income per month.

If you don't pay instalments regularly, the interest rate doubles. 
Example 3 - Write a discursive essay giving your opinion on the following statement: Celebrity endorsement should be avoided in bank advertising campaigns.

\subsubsection{Exercises for introducing culture and raising cultural awareness}

Advertisements are a valuable resource for developing language awareness not just in terms of forms and functions, but also in terms of socio-cultural meanings. For instance, a comparison of advertising for similar products across cultures or the analysis and examination of cultural content can be very practical and insightful for students because of a variety of cultural values and connotations mirrored. Advertisements can sometimes only be understood by members of the targeted culture. However, there are many examples of advertisements with universal appeals. Both can be incorporated into the language classroom.

Example 1 - Compare two advertisements of the same bank service for different cultures (e.g. images of men and women, children, gender roles). What do you notice? What are the main similarities / differences?

Example 2 - This advertisement is aimed at British people. The bank offers different current accounts by asking potential clients How do you like your bank account? along with the image of a teapot. Why do you think a teapot is used in it? What is the message?

Example 3 - Think of the ways to adapt this advertisement to the members of your culture.

\section{Conclusion}

Although opinions towards the use of authentic materials are controversial, it is clear now that authentic materials can be utilized in foreign language learning classrooms and can be beneficial to the learning process as long as they are properly used.

This paper illustrated how advertisements can be potential learning tools in the language classroom and provided concrete examples for learning and teaching vocabulary and grammar, improving oral and written skills, as well as raising cultural awareness in Business English classes. The paper offered an insight into the ways the analysis of this type of text can help both ESP teachers to relate language instruction to particular universal characteristics and ESP students to acquire language more naturally through authentic texts.

Finally, even though authenticity in language education has become somewhat of a trend in recent years, there is still a lack of research on the effects of the use of authentic texts for language learning, especially in relation to students' motivation. In addition, 
more guidelines on the ways to select and incorporate authentic texts are required, since they could be very beneficial for new and innovative task design.

\section{References}

Adams, Thomas. 1995. “What Makes Materials Authentic?” Accessed May 10, 2017. https://eric. ed.gov/?id=ED391389.

Allison, John, and Paul Emmerson. 2013. The Business 2.0 Intermediate. Student's Book. Oxford: Macmillan Education.

Arnold, Ewen. 1991. “Authenticity Revisited: How Real is Real?” English for Specific Purposes 10 (3): 237-244.

Autio, Laura K. 2012. “Authentic Texts as Cultural Mirrors: A Handbook for English Teachers.” Unpublished Master's Thesis. University of Jyväskylä.

Bacon, Susan M. and Michael D. Finnemann. 1990. "A Study of the Attitudes, Motives, and Strategies of University Foreign Language Students and Their Disposition to Authentic Oral and Written Input.” Modern Language Journal 74 (4): 459-473.

Berardo, Sacha A. 2006. "The Use of Authentic Materials in the Teaching of Reading." The Reading Matrix 6 (2): 60-69. Accessed April 20, 2017. http://www.readingmatrix.com/articles/ber ardo/article.pdf.

Beresova, Jana. 2015 "Authentic Materials - Enhancing Language Acquisition and Cultural Awareness." Procedia - Social and Behavioral Sciences 192: 195-204. Accessed May 15, 2017. http:// www.sciencedirect.com/science/article/pii/S1877042815034990.

Breen, Michael P. 1985. "Authenticity in the Language Classroom.” Procedia - Social and Behavioral Sciences 6 (1): 60-70.

Brickman, Bette. 1992. Advertisements in the Basic Skills Writing Class. Accessed May 10, 2017. https://eric.ed.gov/?id=ED352859.

Brierley, Sean. 2002. The Advertising Handbook. Second Edition. London \& New York: Routledge.

Carney, Carmen V. and Matilde Franciulli. 1992. "The Use of Authentic Reading Materials in the Business Language Classroom.” Accessed May 15, 2017. https://eric.ed.gov/?id=ED373538.

Castillo Losada, Cesar A., Edgar A. Insuasty, and Maria F. Jaime Osorio. 2017. "The Impact of Authentic Materials and Tasks on Students' Communicative Competence at a Colombian Language School.” PROFILE Issues in Teachers' Professional Development 19 (1): 89-104. Accessed May 10, 2017. www.revistas.unal.edu.co/index.php/profile/rt/printerFriendly/56763/58142.

Chavez, Monika T. 1998. “Learner's Perspectives on Authenticity.” IRAL 36 (4): 277-306.

Cook, Guy. 1992. The Discourse of Advertising. London \& New York: Routledge.

Cotton, David, David Falvey, and Simon Kent. 2011. Intermediate Market Leader. Business English Course Book. Third Edition. London: Pearson Longman.

Dyer, Gillian. 1982. Advertising as Communication. London: Routledge.

Gilmore, Alexander. 2004. "A Comparison of Textbook and Authentic Interactions." ELT Journal 58 (4): 363-374.

Gilmore, Alexander. 2007. "Authentic Materials and Authenticity in Foreign Language Learning." Language Teaching 40 (2): 97-119. 
Gilmore, Alexander. 2008. "Getting Real in the Language Classroom: Developing Japanese Students' Communicative Competence with Authentic Materials.” Unpublished PhD Dissertation. Nottingham University.

Guariento, William and John Morley. 2001. "Text and Task Authenticity in the EFL Classroom.” ELT Journal 55 (4): 347-353.

Jacobson, Erik, Sophie Degener, and Victoria Purcell-Gates. 2003. Creating Authentic Materials and Activities for the Adult Literacy Classroom: A Handbook for Practitioners. Accessed April 20, 2017. https://eric.ed.gov/?id=ED476482.

Joy, J. John L. 2011. “The Duality of Authenticity in ELT.” The Journal of Language and Linguistic Studies 7 (2): 7-23.

Khaniya, Tirth R. 2006. "Use of Authentic Materials in ESL Classrooms." Journal of NELTA 11 (2): 17-23.

Kramsch, Claire. 1993. Context and Culture in Language Teaching. Oxford: Oxford University Press.

Lazović, Vesna. 2014a. “The Language of Online Bank Advertisements in English.” ESP Today 2 (1): 88-104. Accessed April 25, 2017. http://www.esptodayjournal.org.

Lazović, Vesna. 2014b. "The Significance of Distinctive Lexical Repertoire in British Bank Offers." In Festschrift in Honour of Draginja Pervaz English Language and Anglophone Literatures in Theory and Practice, edited by Tvrtko Prćić et al., 275-289. Novi Sad: Faculty of Philosophy.

Lazović, Vesna. 2015. "Cross-Cultural Analysis of Online Bank Advertisements in English and Serbian.” Unpublished PhD Dissertation. University of Ljubljana.

Lee, Winnie Y. 1995. "Authenticity Revisited: Text Authenticity and Learner Authenticity." ELT Journal 49 (4): 323-328.

Leech, Geoffrey. 1966. English in Advertising: A Linguistic Study of Advertising in Great Britain. London: Longman.

McCarthy, Michael and Ronald Carter. 1994. Language as Discourse, Perspectives for Language Teaching. London: Longman.

Liu, Jiangfeng. 2016. "Adaptation of Authentic Materials in English Listening Comprehension Classes." Theory and Practice in Language Studies 6 (9): 1774-1779.

McDonough, Jo and Christopher Shaw. 1993. Materials and Methods in ELT. Oxford: Blackwell.

McGarry, Dee. 1995. Learner Autonomy: The Role of Authentic Texts. Dublin: Authentik.

Mishan, Freda. 2005. Designing Authenticity into Language Learning Materials. New Jersey: Intellect Books.

Morrison, Bruce. 1989. “Using News Broadcasts for Authentic Listening Comprehension.” ELT Journal 43 (1): 14-18.

Morrow, Keith. 1977. “Authentic Texts and ESP.” In English for Specific Purposes, edited by Susan Holden, 13-17. London: Modern English Publications.

Myers, Greg. 1994. Words in Ads. London: Edward Arnold.

Nation, I. S. P. 2009. Teaching ESL/EFL Listening and Speaking. New York: Routledge.

Nunan, David. 1989. Designing Tasks for the Communicative Classroom. Cambridge: Cambridge University Press.

Osborne, Priscilla. 2005. Teaching English One to One. London: Modern English Publishing.

Peacock, Munro. 1997. "The Effect of Authentic Materials on the Motivation of EFL Learners." ELT Journal 51 (2): 144-156.

Picken, Jonathan D. 2000. "Why Use Ads in Classroom?” JALT Journal 22 (2): 341-355. 
Rees, Nigel. 1982. Slogans. London: Allen \& Unwin.

Richards, Jack C. 2001. Curriculum Development in Language Teaching. Cambridge: Cambridge University Press.

Richards, Jack C. and Richard Schmidt. 2002. Longman Dictionary of Language Teaching and Applied Linguistics. Third Edition. London: Pearson Education.

Rogers, Carmen V. And Frank W. Medley Jr. 1988. "Language with a Purpose: Using Authentic Materials in the Foreign Language Classroom.” Foreign Language Annals 21 (5): 467-478.

Shrum, Judith L., and Eileen W. Glisan. 2000. Teacher's Handbook: Contextualized Language Instruction. Second Edition. Boston: Heinle \& Heinle.

Stamatelou, Maria. 2015. "A Reflection on the Use of Advertisements in Enabling Language Learning in the EFL classroom.” ELTED Journal 17: 27-34. Accessed April 25, 2017. http://www.elt ed.net/uploads/7/3/1/6/7316005/v17_5stamatelou.pdf.

Tanaka, Keiko. 1994. Advertising Language: A Pragmatic Approach to Advertisements in Britain and Japan. London: Routledge.

Thornbury, Scott. 2006. An A-Z of EFL: A Dictionary of Terms and Concepts. Oxford: Macmillan.

Tomlinson, Brian (ed.). 1998. Materials Development in Language Teaching. Cambridge: Cambridge University Press.

Van Lier, Leo. 1996. Interaction in the Language Curriculum: Awareness, Autonomy and Authenticity. Essex: Longman.

Vestergaard, Torben and Kim Schroder. 1985. The Language of Advertising. Oxford: Basil Blackwell.

Widdowson, Henry G. 1983. Learning Purpose and Language Use. Oxford: Oxford University Press.

Widdowson, Henry G. 1998. “Context, Community, and Authentic Language." TESOL Quarterly 32 (4): 705-716.

Widdowson, Henry G. 2003. Defining Issues in English Language Teaching. Oxford: Oxford University Press.

Willis, Jane. 1996. A Framework for Task-Based Learning. Harlow: Addison Wesley Longman. 